\title{
Propagating a Legacy: Undisciplined Drawings and Evolving Technology
}

The University of Auckland's School of Architecture and Planning has a legacy of teaching and producing architectural media that challenges normative representations of the discipline. This was made evident in Auckland during 2017, at the School's centennial exhibition, The Auckland School: 100 Years of Architecture and Planning (Milojevic, Treep, Barrie, \& Gatley 2017). It showed that although technology had changed many representation methods over the years, there has been a continuum of students developing idiosyncratic representation styles and an insistence on students demonstrating a critical position in representation. Since the 1980s, when the Auckland School developed a reputation as a "drawing school" (Barrie 2017: 108), a culture of rigorous media use has been cultivated by many teachers and through the shared memory of many beautiful drawings produced by students and staff. The "critical" approach to media was championed by Sarah Treadwell, who joined the School in 1981, and was originally employed to teach disciplinary types of drawings including plan, section, elevation, and axonometric. Teaching "criticality" can be described as a process of asking students to question why they are drawing in a certain way, and to see drawing, making, and architecture as intrinsically connected. Treadwell taught her students that the use of media was never a neutral act and could be much more than a mechanical representation process. The insistence that drawings could be considered a work of art put her at odds, in a collegial way, with Patrick Hanly, a painter of considerable note and a teacher of freehand drawing at the Auckland School. Treadwell recalled that Hanly refused to see architectural drawing as art. Instead, he saw it as a utilitarian form of representation, separate from his art practice (Treadwell 2016). Moving from the mechanical to the artistic and critical was in line with the theoretical turn and the growth of intellectual thoughtfulness throughout architectural academia. It represented a shift in how drawing, or media as it is now called, was taught at the Auckland School. Media now looked to challenge the dogma of the discipline and ideas of culture, gender, and occupation.

Students at the Auckland School are still encouraged to use representation as a means to explore ideas beyond building-as-usual, or to pursue the founding challenge of the academic journal most closely associated with the School, Interstices, as "the spaces between ideas" (About Interstices 2017). Traditionally, the School 
has taken pride in understanding the periphery, rather than the cutting edge of technology, making students adept at exploring the pitfalls and unintended consequences of technology as well as challenging the discipline through its critical use of architectural and non-architectural media. Thus, Andrew Barrie, who had been a student in the Auckland School in the 1990s and was appointed as its Professor of Design in 2009, has observed that its reputation for representation has broadened in recent years from "drawing" to "making" (Barrie 2017: 125). This article considers how the introduction of architectural software focused solely on "making" in media may neglect a genuine legacy of students producing idiosyncratic graphic styles and exploring the periphery of the discipline in favour of mechanical drawing. It shows that criticality and making must coexist to continue the School's critical legacy in media.

\section{Is the Auckland School's Critical Legacy at Risk from Normalising Software?}

In design studio and media classes, the biggest threat from technology to the School's critical legacy does not come from cutting-edge technologies like virtual and augmented realities or robotics, to name a couple of upstart disruptors, but from architecture's flabby commercial middle, the promise of Building Information Modelling (BIM) software. Software packages like Revit and ArchiCAD are positively historic now, but this technology, more than others, still feels foreign in the studios of the Auckland School. The lack of uptake of industry-standard BIM software by students creates a schism between how the academy makes and how the profession draws. The question remains: To what extent should the Auckland School be a vocational tool for practice? BIM and other software with a bias towards fabrication and construction are viewed here as a normalising force that is descriptive (a "how-to" methodology), rather than speculative. BIM challenges the legacy of the Auckland School's resolve for students developing critical positions. It is argued here that the incorporation of BIM into media courses need not be at the expense of the situated practices concerned with the "what" of architecture if students are taught the disciplinary biases of the technology and use software as one tool among an array of options.

\section{Methodologies over Software}

Many schools across New Zealand and Australia feel pressure from the profession to deliver practice-ready graduates. It is often argued that students require new knowledge acquisition with a bias towards project delivery and media outcomes that are descriptive. The potential of BIM in practice is well established; it dissolves the gap between construction delivery, the production of design intent, and the transmission of information (Garber 2014: 120-27). BIM challenges the primacy of design and the divisions between disciplines as well as notions of collaborative authorship. Architects, as the controllers of the one-to-one digital model, are given back a lost agency during the construction process. All these positives in practice are problematised in academia when academics are pushed by industry to produce graduates that are BIM-ready or, more simplistically, Revit-ready. The resistance in academia is understandable given that the primacy of design in studio is at odds with the woefully poor design features of the BIM software. Peggy Deamer (2011) has championed a need for the integration of BIM 
into architectural education, asking where it should be taught. Is BIM a software issue and, therefore, should it be taught as a support course or an elective? Or is it a new way to design collaboratively?

Architectural practitioners around the world have used BIM and parametric modelling to make innovative design responses that do not adhere to professional norms - to name a couple, the Perot Museum of Nature and Science designed by Morphosis (2012) and Kaohsiung Port Terminal by Reiser + Umemoto of RUR Architecture (2012-16). Similarly, architecture schools worldwide have embraced digital fabrication in their course programmes. Most schools have digital fabrication equipment and many offer programmes that specialise in transdisciplinary design research with a focus on constantly evolving digital technologies. For example, RMIT's Spatial Information Architecture Laboratory (SIAL) offers a Master of Design Innovation and Technology. ${ }^{1}$ There is not a specific programme for digital fabrication at the Auckland School, but students are adept at picking up new technologies for fabricating including the use of robotic arms, 3D printing, and virtual and augmented realities. Barrie has consistently offered a postgraduate design stream focused on fabrication using timber technologies. When designing the learning objectives for a second-year media course at the Auckland School, we wanted to ensure that BIM and parametric techniques did not become the sole content of the course. However, we did want these techniques to assist students with form-making and the production of drawings that communicate fabrication thinking. For these reasons, we incorporated into the course BIM and other architectural software with embedded tendencies towards construction.

This course is taught during the third semester of a Bachelor of Architectural Studies (BAS) and follows on from the more speculative first-year introductions to media. The course is sequenced in the Bachelor's degree to enable students to consider the idiosyncratic nature of their workflows. BIM and parametric software are used to communicate spatial ideas as well as test fabrication and assembly. The course's learning outcomes push students to understand fabrication methodologies over BIM software, like Revit. It is important that BIM is integrated into an existing suite of media skills that assist with learning-by-making. These skills include hand drawing, physical and digital modelling, collage, and animation. The aim is to problematise BIM in relation to an overall workflow made up of a series of relationships between separate media practices.

\section{Representation of Fabrication Methodologies in Architectural Media}

What types of representations are produced when fabrication and assembly are pushed in a media course? Traditionally, drawings that explore fabrication, assembly, and tectonics have been particular tools of investigation in the dialogue between design and realisation. Jean Prouvé called these "constructive ideas" (Picon 1983), with the view that drawing constructs how architects design. Contrary to this insistence that drawing is the driver of design, digital modelling operations give primacy to the one-to-one model as both the object and constructible output of architecture. It is revealing that we revert to traditional architectural representation to tell the story of fabrication. This is because it ties back into the disciplinary history of architectural representation and allows 
abstract critical thinking. Drawings produced by second-year media students include: unfolded / developed surface; exploded axonometric; axonometric; material assembly; façade / elevation study; digital fabrication cutting sheet; analytique-multi-informational drawings; and operative perspective. What knowledge do these drawings privilege and how does this measure up to the School's critical legacy of media?

\section{A Contemporary Disciplinary Bias of the "How"}

Architecture, as a spatial practice, often reveals its disciplinary knowledge through representations. In this respect, media is understood as discursive (Kulper 2013), representing the disciplinary knowledge and discourses privileged during different eras. Amy Kulper invokes Foucault's understanding of a discipline as a regime that produces knowledge. The contemporary operations of architecture's discursive representations reflect a shifting disciplinary bias towards "architectural images whose sole aspiration is to communicate the techniques of their own making” (Kulper 2013: 42). The digital fabrication cutting sheet (see Fig. 1) represents a merging of design and fabrication practice for the discipline. The drawing is a demonstration of its construction and assembly. Kulper claims that contemporary design research and architectural images of fabrication focus on the techniques and protocols of the design process and privilege the "how" over the "what". A danger for media pedagogy is that the technique may become the content. This concern is magnified when trying to incorporate BIM into media courses. Its normalising defaults and design tools overly predict formal outcomes to make all drawings look the same.
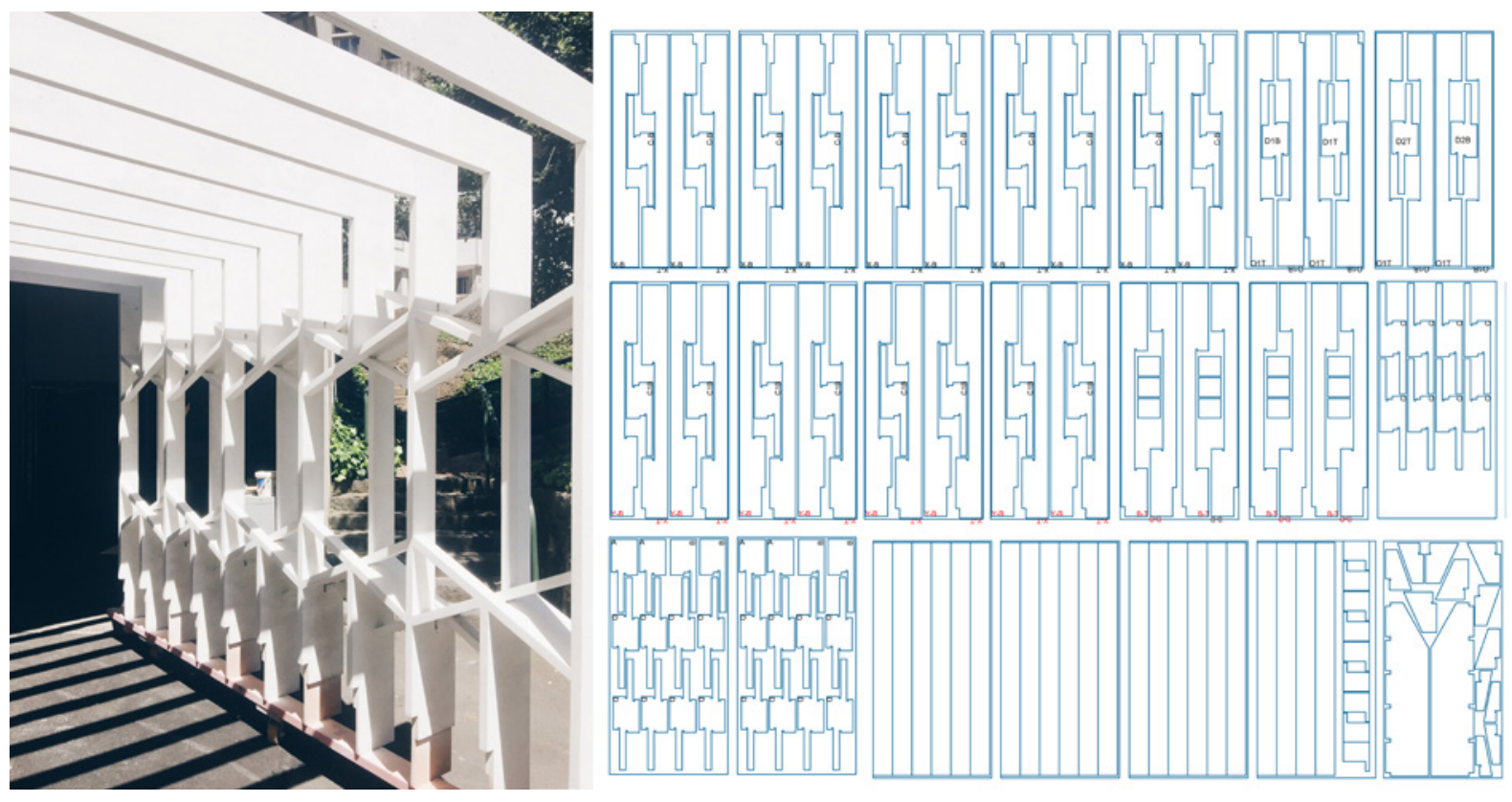

Fig. 1 Louie Tong, MArch(Prof) thesis student, Constructed pavilion and digital fabrication cutting sheet, 2016.
The bias of the "how" overshadows representations of the situated practice, or what Stan Allen refers to as the practice of architecture "marked by this promiscuous mix of the real and the abstract" (2009: xvii). Kulper asserts that:

Architecture's disciplinarity is best represented by recognising the reciprocity of its techniques for making with the political, social and cultural 
contexts it engages. How architects do what they do is a critical aspect of the continuity of the discipline, but our disciplinary discourse must aspire to more (2013: 64).

Alessandro Zambelli in "The Undisciplined Drawing" argues that transdisciplinary drawings, sitting between the thresholds of disciplines, can be described as "undisciplined" (2013: 357-79). This undisciplined character is true for abandoned drawing types such as Piranesi's multi-informational drawings that use perspective in an uncanny, undisciplined manner. It could be argued that Piranesi's drawings are all about technique. However, there is also an implicit critique of the discipline because the drawings reveal the inadequacies of mid-eighteenth-century drawing conventions for communicating his aims. There is a long history of undisciplinary representation at the Auckland School, and it is important that contemporary students understand their drawings and other architectural representations as part of a discourse so that they may explore the space between the "how" and the "what".

\section{Let's Do the Time Warp Again}

At this point, it is worth considering if there are pedagogical lessons to be learnt from the mainstreaming of the digital in the 1990s when this undisciplined intruder challenged the School's legacy of valuing hand-drafted speculative drawings. Studio culture was in flux at the turn of the century, with the introduction of computers and the way students used the design studio. In 1996, Jules Moloney, who was on the staff from 1995 to 2005, advocated for computer use in the design studio rather than their isolation into labs (Barrie 2017: 123). This bold strategy was adopted with poppy-coloured iMacs distributed around the studio spaces on levels 2-4 of the Architecture Building. Before the School refurbishments in 2002, there was an air of the "Wild West" about studio spaces, with students bringing their own furniture and creating ad hoc structures to house their cliques. This led to staff navigating student shanty towns with army-surplus tarpaulin tepees strewn across the studio and drawing boards used for makeshift communal kitchenettes. This lo-fi environment could not be further from the rigid fit-out and clear hierarchy between student and teacher that was instated in 2002 and continues today. Radical student experimentation was valued and rewarded as an outcome of this chaotic studio culture. This was a time before digital skills became prosaic and there was the view among students that their digital knowledge put them apart from practising architects who did not possess such skill. This is not to argue that the quality of the design projects being produced was better than the present; many celebrated student projects of the time had very little traditionally recognisable architectural content and left elder practising architects scratching their heads. The animations of the era seem pixelated and simple, the architectural equivalent of a first-generation cellphone, all chunky and oversized. However, there is something to be said for the spirit of the times, which fostered a level of creative representational radicalism that has scarcely been seen since. The "anything goes" attitude of the studio space enabled a critical adoption of digital tools.

The shift towards new digital representational techniques was made explicit in the comparison of the media of Sean Flanagan and Sam Cuttriss (see Figs. 2 and 3), both of whom were selected to represent the Auckland School in the 2000 
New Zealand Institute of Architects (NZIA) Student Design Awards-an annual competition between New Zealand's three schools of architecture, in which each school is represented by four finalists. Without falling into false dichotomies of analogue and digital, Flanagan's detailed work was characterised by an approach to drawing that was esteemed at the Auckland School. Here, privilege was given to architectural composition that consisted of parts set in relation to other parts, an approach that was considered typical of work in the field of "modernist tectonics”. Cuttriss' proposal for a synthetic expression took theoretical inspiration from American computer scientist and futurist Ray Kurzweil's The Age of Spiritual Machines (1999), which asserted the day was coming where human bodies would become synthetic, and would be eventually replaced by spiritual robots. In Cuttriss' words, his architectural exploration "critically engages the nature of synthetic space, and develops an environment as a continuation, an extension of reality. A substrate within which our synthetic other may exist" (Cuttriss in NZIA Student Design Awards 2001). This can be considered a moment at the Auckland School when architecture made an appearance outside its discipline and declared architecture's ability to merge its own and other disciplinary methods.

Fig. 2 Sean Flanagan, Auckland Regional Civil Defence Station, 2000.

Fig. 3 Sam Cuttriss, Synthetic Expression [Still from animation], 2000.
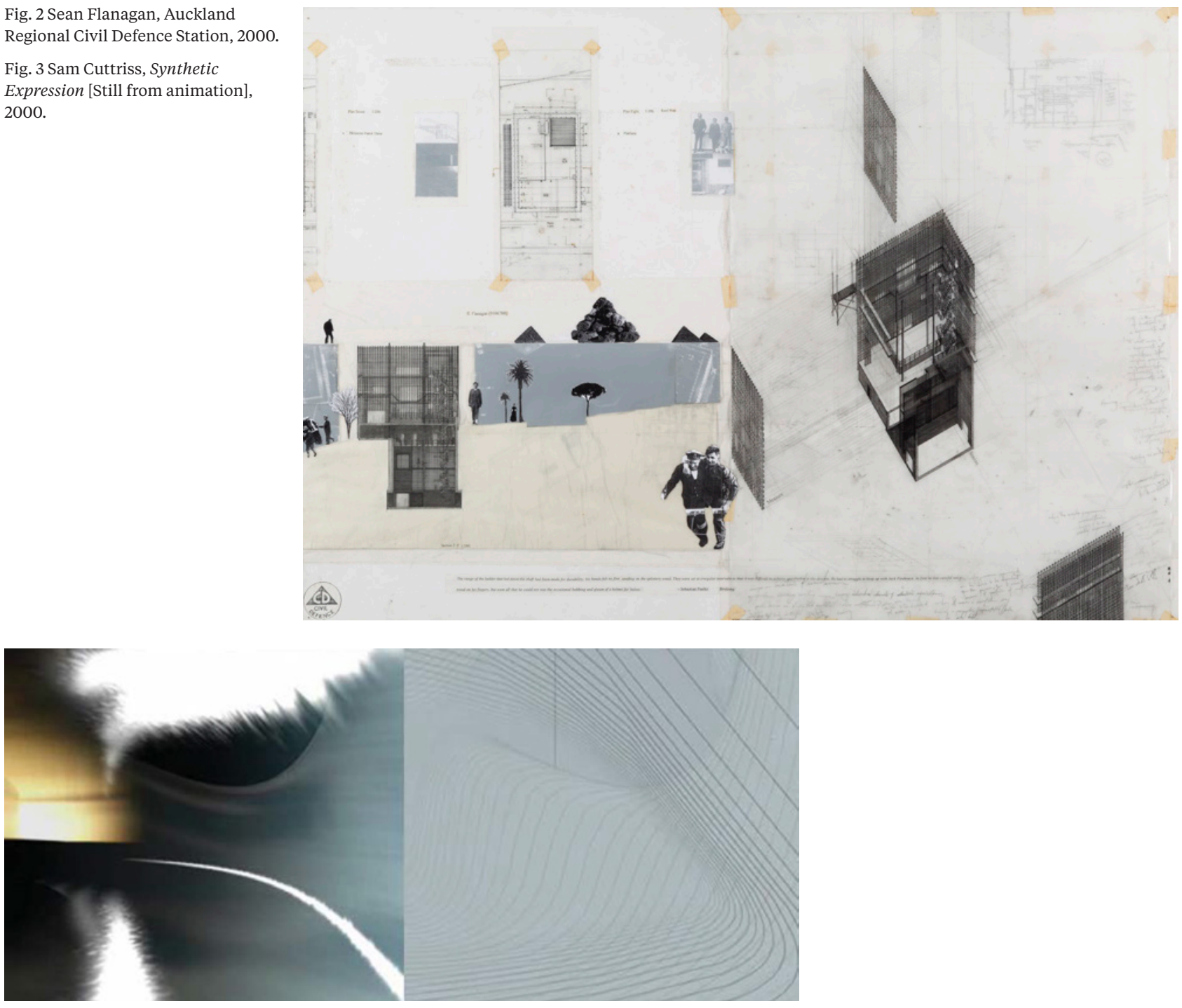
The digital turn of New Zealand architecture schools was slower to become mainstream when compared with others around the world. This was unceremoniously pointed out by Howard Raggatt, an adjunct professor at Melbourne's RMIT and the international judge for the 2000 NZIA Student Design Awards. Raggatt said he was given a "little fright" seeing New Zealand students still clinging to traditional pencils: "Computer-generated designs are entirely ubiquitous at RMIT," he explained,

I would be shocked if anything else appeared-in fact I doubt the students can use a drawing board or physically write in the traditional sense. So, to walk into a room where graduates are producing work that is not a reproduction or output, but crafted like an art work, was a little shocking-like walking into a time warp (Raggatt in NZIA Student Design Awards 2001: 75-76).

Given Raggatt's penchant toward the new and digital it was not surprising that the winning project for the first year of the new millennium was a boundary-pushing digital animation full of speculative optimism, but bereft of human presence and traditional architectonic craft. A lament for the death of hand drawing followed, alongside recognition of an emerging digital craft (Davis 2009: 82-91) and media outcomes exploring new fields that included film animation, web design, and gaming. Although Cuttriss pushed furthest away from the School's legacy of valuing hand-drafted speculative drawings as outcomes, it did not diminish its insistence on the aesthetic and speculative at the forefront of emerging digital representational techniques. In retrospect, this was less about the death of the handcraft than the emergence of new areas of representation and hybrid experimentation.

The success of Cuttriss' proposal encouraged other students to explore the "digital", as it was referred to at the time. In effect, it was an un-nuanced marker for anything to do with a computer. In 2003, a close-knit group of students from the Auckland School produced an exhibition titled Quickenings: Digital Film Architecture (Bellard \& Chua 2003). The exhibition explored the intersection of film, architecture, and the digital through final-year student work made between 1999 and 2002. Stand-out work included Melanie Tonkin's Emotional City (2002), an animation that examined a glitch in a prosaic landscape, resulting in a Turner-esque dematerialised space that challenged traditional orthographic and perspective representation (see Fig. 4). Equally challenging was Eu Jin Chua's Wallpaper (2000), which questioned the norms of "good taste" in architectural City [Still from animation], 2002. representation. The animation was a pointed response to disparaging comments

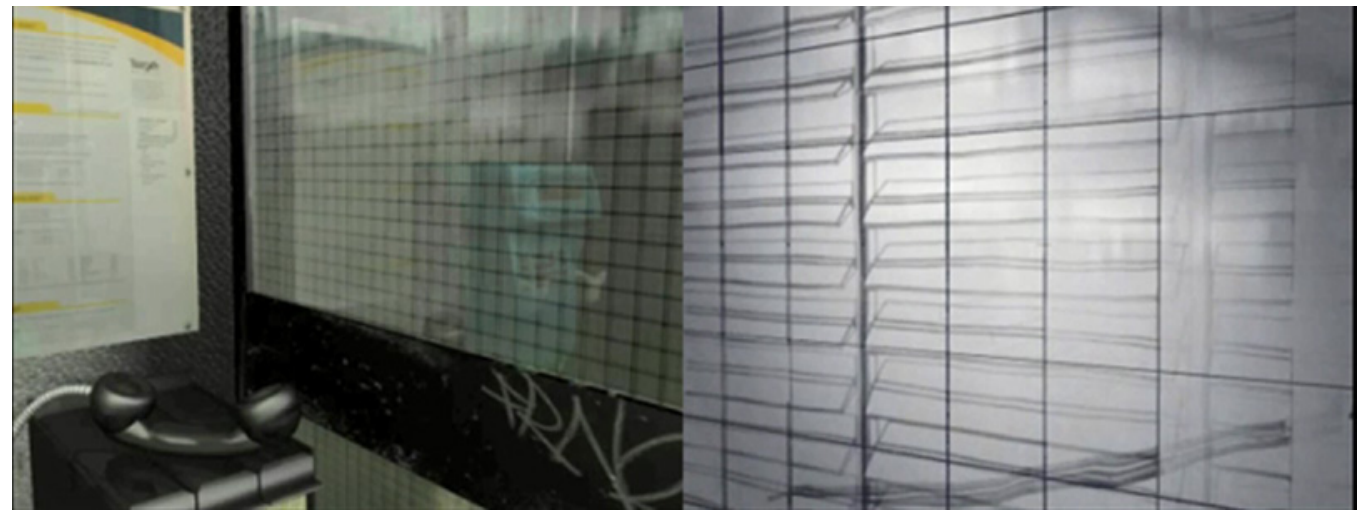


about interior design as "wallpaper", implying that interior design was the lesser art form compared to architecture.

The exhibition highlighted the transdisciplinary ambition of the Auckland School and its ongoing legacy of critique aimed at destabilising the bastions of architectural discipline. Sarah Treadwell summed up the zeitgeist in the Quickenings exhibition catalogue, drawing allusions to the weather as a metaphor for digital space and its connection to media practice:

Weather is always about future conditions mapped with signs from the past. Architecture, too, is caught in a complex oscillation between representations weighed down by history and technologies that imagine a future in the present. Anxiety about weather is a consequence of its unpredictability, and architecture suffers a similar anxiety as it negotiates new forms arising from anticipated conditions and changing technologies. Weather and architecture, seemingly opposed states, can be seen to share aesthetic and social inclinations (Treadwell 2003: 20-22).

Quickenings' animations presented digital technique as content and, in an "undisciplined" moment, they also challenged the discipline's orthodoxies.

\section{Fast-Forward to Now: Making, Hybridity, and the Undisciplined Drawing}

If we take this "undisciplined" approach as a lesson about contemporary challenges in teaching architectural media, we can imagine how asking students to invest in the idea of fabrication could produce diverse media outcomes. Since the Auckland School's first digital turn, there has been a consistent emphasis on the hybrid use of media pointing to a continuation of explorations that attempt to reveal the "how" and the "what" of Kulper's dichotomy. Treadwell advanced a hybrid analogue and digital approach as the most productive way to solve architectural problems. With this model, students should be encouraged to move from one mode of representation to another to discover the potential and anomalies of each, as teaching media is not about the "technical acquisition of a skill, a digital skill, but rather it's a mode of critical thinking about the subject" (Treadwell 2016). This kind of hybridity suits the contemporary way that students learn the use of digital modelling, and BIM is one subset of media that students must master, along with physical modelling, digital fabrication, sketching, animation, and virtual and augmented realities.

Second-year media, as taught in 2017, continues the Auckland School's legacy of making, hybridity, and undisciplined drawing, where students are encouraged to examine the content of the construct represented. Students begin with sketching and generative model-making, which becomes the basis for a digital/BIM model that allows the students to focus on how to communicate fabrication and occupation. From here, digital collage and cut-out techniques are used to embed narrative into architecture, allowing stories to unfold. Drawing styles jump from fantastical to technical and are used to discover narrative content that exceeds the parameters of construction. The hybrid use of media is a consequence of a design workflow particular to each student assembling a portfolio with a range of media outputs. This forces the 
student to think about the specific aspects of their practice and helps them to explore relationships between different types of media.

The portfolio of Vinayak Garg (see Fig. 5) exemplifies the work of recent and current second-year media students. He examined the narrative potential of merging fabrication ideas with a hybrid collage of media that included collage (cut out and digital), fabrication cutting sheets, plaster models from digital patterns, and animation. Garg's drawings are loaded with references to architectural precedents, from the drawn style of Superstudio to the built work of Louis Kahn. The construct's surface is embedded with characters from Hieronymus Bosch's oil painting, The Garden of Earthly Delights (ca. 1490-1505). An animation plays with the conventions of the exploded fabrication drawing. Similarly, Fin Forster's drawing for the course (see Fig. 6) uses a hybrid media process to test how a construct may be occupied and operated. Both drawings evoke worlds with numerous meanings and tectonic possibilities.
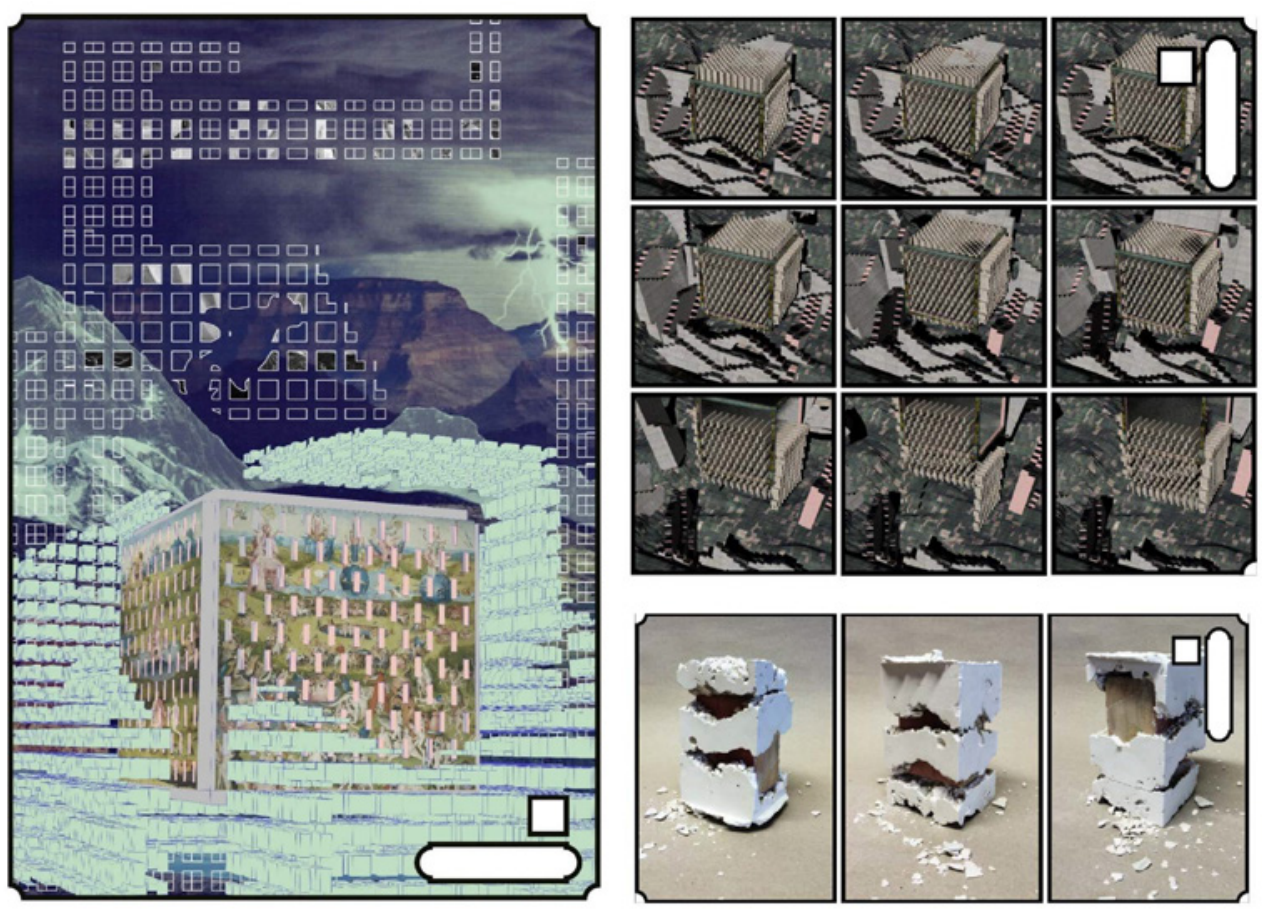

Fig. 5 Vinayak Garg, second-year media student, Collage combining plaster physical models, made from a BIM model, and animation, 2016.
The student work produced in this course reveals an interesting area of productive digital speculation that merges the fabrication potential implicit in BIM, Grasshopper, and collage techniques. Sam Jacob sees the speculative value in "collage culture" that privileges curation, editing, narrative, assemblage, and Photoshop. This type of post-digital representation offers a reconnection with architectural images as "polemical assemblages". Jacob states,

The digital drawing tools we now have at our disposal have changed the relationship we now have to images-both as we consume and make them. But at the same time these tools can allow us to engage with the long disciplinary history of architectural representation (2017). 


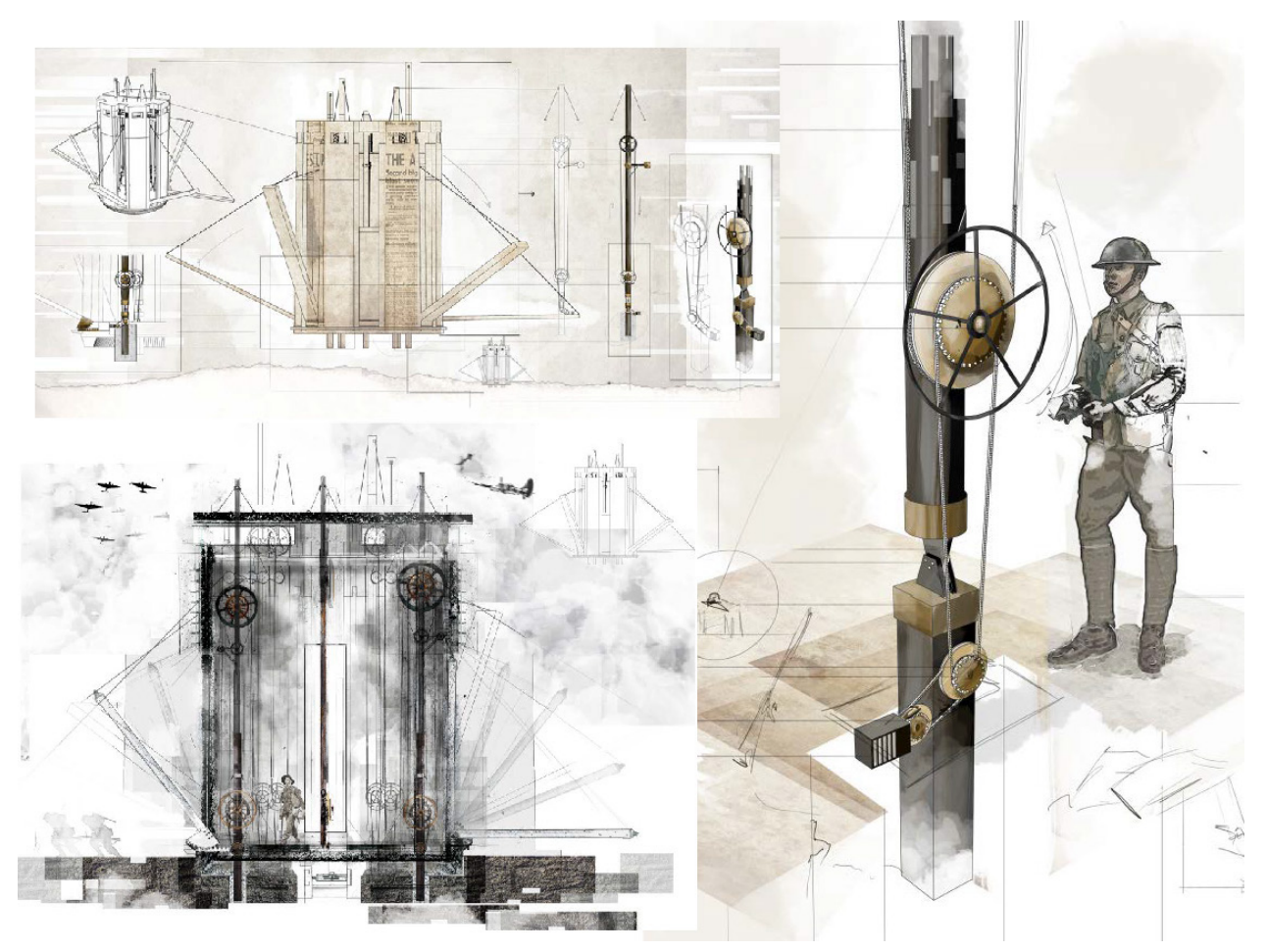

Fig. 6 Fin Forster, second-year media student, Hybrid drawing, 2017.
The hybrid collages point to ways forward that continue the speculative legacy of media while embracing fabrication and BIM. The introduction of BIM into studio, while important, should not be a primary aim without critically positioning it within a workflow. BIM is not implicitly obvious in the drawings; it is subsumed in the process, making part of the drawing possible and leading the work to a place that embraces fabrication, materiality, texture, and craft unexpectedly. These hybrid drawings express an interest in a compositional tectonic of parts. Curiously, this is a move back to Flanagan's tectonic expression as distinct from Cuttriss' atmospheric surface with students toggling between the abstract and the real.

Since the 1990s, the syllabus has shifted from teaching the disciplinary drawing of plan, section, elevation, axonometric, and physical modelling. Digital modelling and animations have been added to this media suite. Now we accept that media practice informs design. We talk about communicating fabrication thinking and encourage students to embrace the engagement potential of augmented and virtual realities. One element that is consistent between eras is the desire to teach students to understand the privileged disciplinary knowledge behind media positions and to raise questions about what constitutes creative engagement with drawings and technology. In this way, BIM, as a tool for the communication of fabrication thinking, can be used critically rather than merely describing learning outcomes. It is vital that we encourage students to think beyond the act of representation, demonstrate their understanding of drawing as part of a larger discourse, and produce undisciplined drawings where appropriate. In this way, we will see the propagation of the Auckland School's critical legacy. 


\section{REFERENCES}

About Interstices (2017).

Interstices: Journal of Architecture and Related Arts. Retrieved from http://interstices. ac.nz/about-interstices/

Allen, S. (2009). Practice: Architecture, technique and representation. New York: Routledge.

Barrie, A. (2017). "Architecture to a fault": The postmodern years. In J. Gatley \& L. Treep (Eds.) The Auckland School: 100 years of architecture and planning (pp. 102-127). Auckland: School of Architecture and Planning, University of Auckland.

ENDNOTES

Bellard M., \& Chua, E. J., curators. (2003). Quickenings: Digital film architecture. Auckland: Film Archive, February 20-April 2.

${ }^{1}$ For an overview of RMIT's Master of Design Innovation and Technology (MDIT) coursework programme, see http://www.sial. rmit.edu.au/sial-study/
Chua, E. J. (2000). Wallpaper [animation / MP3 file]. Auckland.

Davis, M. (2009). Maintaining the abstract critical facility in post-digital drawing practice. Interstices: Journal of Architecture and Related Arts, 11, 82-91.

Deamer, P. (2011). Introduction. In P. Deamer and P. G. Bernstein (Eds.), BIM in academia. New Haven, CT: Yale School of Architecture.

Garber, R. (2014). No more stopping. In BIM design: Realising the creative potential of building information modelling ( $\mathrm{pp}$. 120-127). Somerset, GB: Wiley.

Jacob, S. (2017). Drawing as project: Post-digital representation in architecture. Retrieved from http:// strangeharvest.com/ wp17/?p=4047

Kulper, A. C. (2013). Representing the discipline: The operations of architecture's discursive imagery. Architecture and Culture, 1(1), 42-66.

Kurzweil, R. (1999). The age of spiritual machines: When computers exceed human intelligence. New York: Viking.

Milojevic, M., Treep, L., Barrie, A., \& Gatley, J., curators. (2017). The Auckland School: 100 years of architecture and planning. Auckland: Gus Fisher Gallery, September 8-November 4.
NZIA Student Design Awards. (2001). Architecture New Zealand, January-February, 75-78.

Picon, A. (1983). Is drawing dead? In Jean Prouvé: I'ldée constructive. Paris: Dunod.

Tonkin, M. (2002). Emotional city [animation / MP3 file]. Auckland.

Treadwell, S. (2003). Digital weather: Pacific space. In E. J. Chua \& M. Bellard (Eds.), Quickenings: Digital film architecture [Exhibition catalogue] (pp. 20-22). Auckland: The NZ Film Archive.

Treadwell, S. (2016, September 28). Personal interview with $L$. Treep, Auckland.

Zambelli, A. (2013). The undisciplined drawing. Buildings, 3,357-379. 